pertion of the blood, that the practice of giving opinm and other astringents to arrest the intestinal discharges will continue more or less, in spite of frilure and disappointment, until it can be clearly shown that the state of collapse has an entirely different origin: and cause from that which the theory in question assumes.

[To be continued.]

\section{Original Communtations.}

\section{CASE OF PUERPERAL TETANUS, FOL- LOWING ABORTION AND PLUGGING OF THE VAGINA.}

By Josmph Blackshaw, Esq., Stockport.

ON Saturday, November 8th, 1864, I was called to see Mrs. H., aged 48 years, the mother of a numerous family, of a highly nervous temperament, and whose general health had previously suffered from some domestic anxieties.

She was in bed, very faint from profuse hæmorrhage from the uterus. I made an examination, and detected an ovum of about ten weeks' growth within the os uteri. In consequence of the amount of the hæmorrhage, I plugged the vagina; ordered cold applications, stimulants, and the usmal astringent remedies, including the ergot of rye; and she rallied in the course of the following day. The plag remained in the vagina twelve or fifteen hours, and, when removed, was not again resorted to, as the hrmorrhage had almost ceased, and the ovum was expelled a few hours afterwards. She progressed satisfactorily for about nine days, at the end of which time she was able to sit up, and about to leave her room. Thinking it unnecessary for me to continue. my visits daily, I left her with directions to report to me her progress.

On the day following (Tuesday), just ten days from my first visit, I was unexpectedly requested to see her. She thought she had taken cold, and was then complaining of great stiffness of the deep-seated muscles of the neck and throat, with difficulty of swallowing, and was unable to open her mouth perfectly. As there was some febrile excitement, she was ordered to remain in bed, and to take a saline mixture with an aperient; to use hot fomentations ; afterwards hot moist bran; to steam the fauces; and, if possible, to use a gargle.

On the two following days, Wednesday and Thursday, the painful tension of the masseters, as well as the muscles of the neck and throat, had so greatly increased as to prevent deglutition and bring on a state of perfect trismus. On Thursday afternoon and evening, the tetanic seizures became increasingly frequent, producing great muscular rigidity, contorsion of features, and slight opisthotonos. During the paroxysm, the pulse was small and feeble; but the consciousness was entire throughout. She continued in this state until Saturday evening, the tetanic opasms and opisthotonos gradually becoming more severe, when she died from exhaustion, five days from the fit setting in of the tetanic symptoms.

Drifig to tho clepuched state of the jaws, little was done in the way of treatment, beyond a little counteration to the ofine; the administering of a turpentine epom; and the removal of fæcal accumulations, whík might prove a possible source of spinal irritation.

Puerperal tetanus is a very rare species of that disease in this crimato; and this must be my apology for this communication. I have been in practice in this town for more than thirty years, the greater part of which I have been medical officer to a large district of a Poor-law union including the union workhouse, and must have attended three or four. thousands of women 'in labour at different periods of utero-gestation; and this is the first case that has occurred in my public or private practice, or, so far as I can learn, in that of the oldest obstetrician. either here or in Manchester, with the exception of one case mentioned by Dr. Whitehead. Dr. Radford considers it a rare disease, but has known it to occur. Mr. Roberton, of the same city, also says that obstetric tetanus is a novelty to him, and that he has never seen it during a long and laborious practice. Nor is the disease one asitally recoginised in treatisles on midwifery;and the diseases of lying-in women. The extreme rarity and infrequency of this disease, notwithstanding the various lesions from the application of instraments, manual interference, turning and other violence that the uterus must often sustain in protracted and difficult labours, points to a very different state of 'the' nervous system frora that which gives rise to traumatic tetanus in the yarious external injuries to which the body is subjected. Physiologists attribute this to the uterus receiving its nerves from the great sympathetic. It may be so. But of what that peculiarity of the nervous system consists in these cases, where the irritation from the uterus, as in the case of Mrs. H., is propagated to the cerebro-spinal system, is still shrouded in mystery. We can only say that, in the case of my patient, cold applied to the body, previously lowered by mental anxiety and loss of blood, may have given rise to a otate of reflex spinal irritation, followed by tetanus; though probably, in ten thousand other in stances, the same exciting causes would produce no such effects.

I regret that chloroform was not tried, as, besides the good effects it is said to have in convulsive diseases, it presents facilities of application where no internal remedy can be given.

My object in this communication is rather to seek than give information ; and I trust that some of our more learned associates will ere long throw some fresh light upon this class of diseases, which are yot among the opprobria medicorum.

\section{CASE OF RUPTURE OF THE UTERUS : ABDOMINAL. SECTION : SUBSE- QUENT PREGNANCIES.}

\section{By Samuer S. Dxer, M.D., Ringwood.}

JuLy 29th, 1862, 8 P.M., I received a note from $\mathbf{M r}$. Clifton of Fordingbridge, stating that he was in at tendance at a case of midwifery at Mockbeggar, midway between our respective residences; that the uterus had ruptured, and he believed the woman would die. He requested that I would meet him there at once. I went immediately, and found the patient, Mary Ann Woods, aged 37, in a state of great prostration, and evinging signs of severe shock to the nervous system. She was quite sensible; the pulse was quick and fluttering; the breathing short and hurried; the skin cold, and covered with perspiration, which stood in large drops on her face and forehead. On placing the hand on the abdomen, which was very tender, the outline of a fotus could be distinctly felt lying beneath the parietes; the uterus, contracted to the size of the foetal head, was evident; and, on examination per vaginam, it was clear that the uterus was emptied of what it had containod. This was the fourth labour of the woman; 